\title{
The Effects of Plate Presentation on Calorie Estimates and Consumption Decisions-An Abstract
}

\author{
Courtney Szocs and Sarah Lefebvre
}

\begin{abstract}
The way that food is presented on a plate (i.e., plate presentation) can influence consumers' judgments and decisions. Not surprisingly, some restaurants have started to use plate presentation strategically. This research investigates unintended consequences of plate presentation in terms of influencing consumers' portion size perceptions and consumption. We ask: would presenting a portion of food vertically (i.e., stacked up on a plate) versus horizontally (i.e., spread out on the plate) influence consumers' portion size perceptions? And how might vertical (vs. horizontal) plate presentation influence consumers' consumption volume?

We draw on prior research related to size perceptions and characteristics of the eating environment and link it with work in the domain of the psychophysics of salience. We propose that in typical dining situations the length and width of the food portion (i.e., the surface area) will be relatively more salient than the height dimension leading foods with larger surface areas to be perceived as larger. Furthermore, for equal volumes of food, portions presented horizontally would have a greater surface area and should therefore be perceived as larger than portions of food that are presented vertically. We also propose that because consumers' perceive portions of food presented vertically as smaller they will eat a greater volume of food when the portion is presented vertically (vs. horizontally).

The results of four studies support our predictions and show that plate presentation can systematically influence consumers' portion size perceptions and consumption volume. This effect appears to be driven by consumers' tendency to base portion size evaluations on the length and width dimensions of the plated food since these dimensions would be relatively more salient than the height dimension in typical dining situations.
\end{abstract}

References Available Upon Request.

\author{
C. Szocs $(\bowtie)$ \\ Portland State University, Portland, OR, USA \\ e-mail: courtne@pdx.edu \\ S. Lefebvre \\ University of Central Florida, Orlando, FL, USA \\ e-mail: sarah.lefebvre@ucf.edu
}

